일반논문-10-15-1-01

$$
\begin{gathered}
\text { 영상 인페인팅을 이용한 고품질의 가려짐 영역 보간 방법 } \\
\text { 김 용 진a), 이 상 화), 박 종 일)^ }
\end{gathered}
$$

\title{
A High-Quality Occlusion Filling Method Using Image Inpainting
}

\author{
Yong-Jin Kim ${ }^{\text {a) }}$, Sang Hwa Lee ${ }^{\text {b) }}$, and Jong-Il Park ${ }^{\text {ał }}$ \\ 요 약
}

본 논문에서는 한 장의 기준 영상과 그에 상응하는 참 깊이 맵을 이용하여 가상의 다중 시점 영상 생성 시 발생하는 가려짐 영 역 보간 방법을 제안한다. 이 방법은 영상 인페인팅 기술과 각각의 깊이 정도에 따른 층별 보간 기술을 이용한다. 우선, 기준 영 상을 깊이 정보에 따라 여러 개의 층으로 분할한다. 각각의 층에 대해 가려짐 영역 내의 화소들은 영상 인페인팅 기술을 이용하 여 보간한다. 마지막 단계 에서 개별적으로 보간된 층 영상들은 하나로 합성되어 가상 시점의 영상을 이룬다. 영상을 깊이 정보에 따라 분할함으로써, 각 깊이 정도에 대한 텍스처의 연관성을 보존하며 보간할 수 있으므로 기존의 방법에 비하여 보다 정확하고 세밀한 가려짐 영역 보간이 가능하다. 본 논문에서는 여러 가지 실험 결과를 통하여 제안한 방법의 효율성을 입증하였다.

\begin{abstract}
In this paper, we propose a method for filling out the occlusions in generating multi-view images from one source image and its ground-truth depth image. The method is based on image inpainting and layered interpolation. The source image is first divided into several layers using depth information. The occlusions are interpolated separately in every layered image using the image inpainting algorithm. Finally, the interpolated layered images are combined to obtain different viewpoint images. Interpolating occlusions with depth-correlated texture information that is contained to each layer makes it possible to obtain more detailed and accurate results than previous methods. The effectiveness of the proposed method is shown through experimental results.
\end{abstract}

Keyword : Image inpainting, View synthesis, Occlusion

\section{I. 서 론}

사용자들의 몰입감과 임장감에 대한 요구는 나날이 증대

a) 한양대학교 전자통신컴퓨터공학부

Dept. of Electrical and Computer Engineering, Hanyang University b) 서울대학교 전기공학부

Dept. of Electrical Eng. and Computer Science, Seoul National University ‡ 교신저자 : 박종일 (jipark@hanyang.ac.kr)

※ 본 연구는 한국문화콘텐츠진흥원에서 지원하는 " $\mathrm{CT}$ 기반 미디어 아 트 전시를 위한 저작도구 기술 및 지능형 전시 공간 구현 기술 개발" 사업의 일환으로 수행하였음.[과제 번호: 2-09-1205-001-10988- 15-005] - 접수일(2009년4월 30 일),수정일(1차:2009년8월21일,2차: 12 월30일),게재확정 일(2009년12월30일)
되면서 3 차원 미디어 컨텐츠의 수요가 늘어나고 있으며, 최 근에는 3 차원 영상처리에 관련한 연구가 활발히 수행되고 있다 ${ }^{[1,2,6]}$.

일반적으로 3 차원 영상 디스플레이는 하나의 스테레오 영상을 기반으로 행해진다. 그러나 스테레오 영상은 오직 두 시점(view)만을 가지므로 다시점 3차원 디스플레이에는 적합하지 않다. 이러한 문제를 해결하기 위하여 모든 시점 에서의 영상을 획득하여 전송하는 방법을 생각해 볼 수 있 다. 그러나 그러한 방법은 매우 많은 데이터양으로 인하여 전송 시 많은 대역폭(bandwidth)을 점유하는 문제점이 있 
으며 영상의 획득 단계에서도 다수의 카메라를 이용하여야 하는 등 큰 비용을 소모한다. 따라서 소수의 참조 시점 영상 을 이용하여 다수의 중간 시점 영상들을 합성하는 중간 시 점 영상 합성 방법이 현재 가장 실용적인 대안으로 판단되 고 있다.

그 중에서도 한 장의 영상과 깊이 맵을 이용하여 가상 시점 영상을 생성해 내는 연구가 활발히 진행되고 있다 ${ }^{[1]}$. 또한, Z-cam이나 레이저 스캐너로 획득한 깊이 맵이 아닌 한 장의 영상과 영상 내부에 포함된 정보를 이용한 깊이 맵 생성 방법이 연구되고 있다 ${ }^{[3,5]}$. 그러나 단일 영상 기반의 다시점 영상 합성 방법은 깊이에 따른 각기 다른 화소 (pixel)들의 이동으로 인하여 가려짐 영역(occlusion)이 발 생하고, 정보가 없는 이러한 가려짐 영역으로 인하여 정확 한 합성 영상을 얻기 힘들다. 그러므로 이러한 가려짐 영역 에 대한 효과적인 보간(interpolation)방법에 대한 연구가 필요하다.

본 논문에서는 한 장의 기준 영상과 그에 상응하는 참 깊이 맵(ground-truth depth map)을 이용하여 여러 곳의 주 변 시점에서의 영상 합성 방법을 제안하였다. 본 방법은 영 상 인페인팅(image inpainting)과 계층적 보간(layered interpolation)을 이용하여 가려짐 영역에 대한 보간을 수행한 다. 우선, 기준 영상을 그 깊이 정보에 따라 다수의 영역으 로 분할한다. 각각의 분할된 영상에서 가려짐 영역 상의 화 소들은 영상 인페인팅 알고리즘을 통하여 보간 한다. 최종 적으로, 보간 된 각 영역 영상들은 하나의 영상으로 합성되 어 가상 시점 영상을 이룬다. 가려짐 영역을 깊이 정보를 고려하여 보간함으로써 기존의 방법에 비하여 보다 깨끗하 고 세밀한 결과 영상을 획득할 수 있다.

2장에서는 관련연구에 대하여 간략히 살펴보고 본 논문 에서 제안하는 시스템의 개요를 제안하였다. 3 장에서는 본 논문에서 제안하는 시스템의 처리 과정과 세부 단계에서 사용된 알고리즘에 대하여 설명하였다. 4장에서는 그 결과 와 결과에 대한 분석을 나타내었으며, 마지막 5장에서는 제안한 시스템에 따른 실험 결과를 토대로 결론을 제시하 였다.

\section{II. 관련 연구}

\section{1. 가상 다시점 영상 합성 시스템}

지금까지 다양한 가상 시점 영상 합성 시스템이 제안되 었다. 일반적인 가상 시점 영상 합성은 소수의 한정된 시점 영상을 이용하여 다수의 중간 시점의 영상을 합성하는 방 법을 사용한다 ${ }^{[12.13]}$. 이 방식은 기본적으로 두 개 이상의 시 점의 위치와 획득 된 영상의 기하학적인 관계를 이용하게 된다. 시점의 위치와 영상들 간의 기하학적 관계는 행렬의 형태로 나타낼 수 있으며, 시점의 변화는 시점과 영상간의 관계를 표현하는 행렬의 회전과 평행 이동 연산으로 나타 낼 수 있다. 따라서 카메라의 위치와 영상간의 기하 관계를 통해 임의 시점의 영상을 합성 할 수 있다. 하지만 임의의 시점을 이용하여 영상을 합성하게 되면 각 시점 영상간의 색상 정보와 깊이 정보가 일치 하지 않아 특히 영상 내 윤곽 선 부근에 오차가 많이 발생하여 실제 영상에 비해 사실도 가 떨어진다. 이런 윤곽선 불일치 문제를 해결하고 생성된 합성 영상의 화질을 개선하기 위해서 최근에는 영상 내에 서의 경계 영역을 추출하여 겹쳐지는 부분들에 대하여 투 명도를 조절하여 보다 사실적인 영상을 획득하는 방법 ${ }^{[15]}$ 이 연구되었다. 혹은 두 개 이상의 시점 영상으로부터 색상 정 보와 깊이 정보를 획득하여 도출 된 각 시점에서의 영상 정보 간의 기하학 관계를 이용하여 3 차원 보간하고 가려짐 영역을 보간 함으로써 가상 시점의 영상 화질을 향상시키 는 방법 ${ }^{[16][17]}$ 등이 연구 되었다. 하지만 이 방법들은 두 개 시점 이상의 영상 정보가 필요하기 때문에 본 논문이 가정 하는 단일 시점 영상 합성 방법에 적용하기 어렵다. 단일 기준 시점에서의 가상 영상 합성을 위해서는 Fehn이 제안 한 단일 기준 영상과 그에 상응하는 깊이 맵을 기반으로 영상 획득에서부터 압축, 전송, 합성 과정을 포괄하는 전체 적 프레임웍(framework)을 들 수 있다 ${ }^{[1]}$. Fehn은 가려짐 영 역에 대하여 가우시안(gaussian) 보간을 적용하였다. 또한 Liang Zhang은 가우시안 보간 대신 비대칭적(asymmetrical) 가우시안 필터로 보간하는 방법 ${ }^{[18]}$ 을 제안하였다. 하지 만 이와 같은 방법은 보간하고자 하는 픽셀 주변의 값들에 대한 보정 값이기 때문에 세밀한 보간이 어려워 실제 입체 
디스플레이에 적용하였을 경우 사용자로 하여금 시각적인 거슬림을 느끼게 하는 요인이 된다.

\section{2. 영상 인페인팅}

영상 인페인팅 기술은 최근 영상 신호 처리 분야에서 주 목 받고 있는 분야로써 다양한 방법들이 제안되고 있다. 과 거에 영상 인페인팅을 위하여 사용된 방법은 대부분 보간 법에 ${ }^{[7]}$ 에 의한 것이었으나 보간법을 통한 방법은 에러가 전 파(propagation)되는 특성이 있기 때문에 넓은 영역의 보간 을 위해서는 적합하지 않다. 이러한 이유로 더 나은 보간 방법을 찾고자 활발히 연구가 진행되었다.

Efros등은 텍스처 합성 기술을 소개하였다. 텍스처 합성 기술은 제한된 텍스처를 합성하여 새로운 텍스처를 생성하 는 기술이다 ${ }^{[8,9]}$. 또한 그들은 웹(web) 상의 방대한 영상 자 료를 이용하여 이미지 정보의 화소가 없는 부분을 보간하는 획기적인 알고리즘을 제안하였다 ${ }^{[10]}$. Sun 등은 영상 보간 시 구조체가 왜곡 되는 현상을 보완하기 위해 사용자로 하여금 직접 구조의 모양을 선택 할 수 있도록 하는 방법을 제안하 였다. Criminisi등은 하나의 영상 내에는 수많은 화소 정보 가 담겨 있다는 전제하에 Efros의 텍스처 합성 방법을 토대 로 보간할 영역에 대하여 가장 적절한 텍스처를 화소 정보 가 존재하는 다른 영역에서 찾아 차용하는 방법을 제안하였 다다. 이른바 모형 기반 방법이라 불리는 이 방법은 그 이후 Drori와 Sun등에 의해 발전되고 보완되었다 ${ }^{[11,14]}$.

본 논문에서는 영상 인페인팅을 위해 Criminisi등이 제안 한 방법을 사용하였다. 본 방법은 정보가 없는 영역에 대하 여 외곽 쪽의 경계(contour)상의 화소부터 한 화소씩 차례 로 우선순위(priority)를 정하여 보간하는 방법으로 차용할 화소로는 정보가 있는 영역 상의 가장 유사도가 높은 화소
가 선택된다. 일반적으로 가려짐 영역을 보간하기 위해 적 합한 텍스쳐는 가려짐 영역의 위치 근처에 존재하므로, 참 조할 소스영역은 보간 해야 하는 영역의 크기를 고려하여 적절한 거리 내의 영역으로 제한함으로써 속도를 증가시켰 다. 그림 1에 Criminisi가 제안한 알고리즘을 이용한 영상 인페인팅의 결과를 예시하였다.
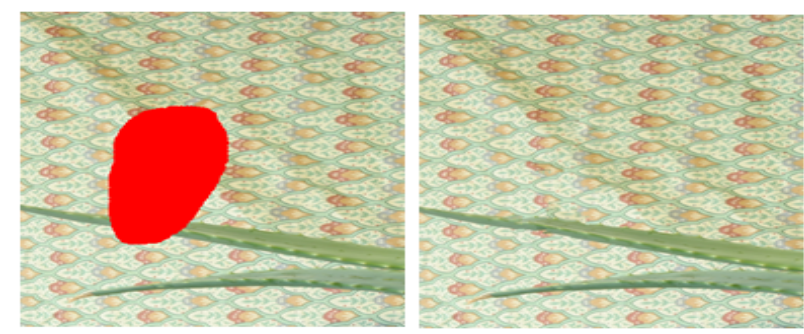

그림 1. 영상 인페인팅을 이용한 텍스처 보간의 예

Fig 1. A example of texture interpolation using image inpainting

\section{III. 가상 다시점 영상 합성}

제안한 시스템의 개괄적인 블록도를 그림 2에 나타내었 으며 처리 과정의 핵심 부분은 다음과 같이 3 단계로 나누어 진다.

단계 1. 기준 영상의 계층적 분리

단계 2. 각 계층 영상에서의 영상 인페인팅 보간 수행

단계 3. 보간된 계층 영상들의 합성

그림 3 에는 단계1-3의 전반적인 처리 구조를 블록 다이 어그램으로 나타내었다. 단계 1 에서 단계 3 까지의 처리과 정은 원하는 만큼의 시점 영상들이 합성될 때까지 반복적

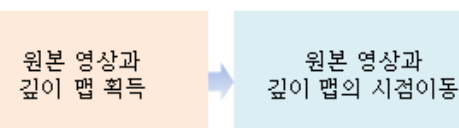

깊이 맵의 화소값 분포에 따라 원본 영상을 분할

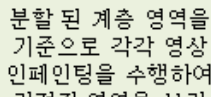

인페인팅을 수행하여 가려짐 영역을 보간
가상 시점의 원본 영상 및 깊이 맵 획득

반복: 다시점 영상 획득

그림 2. 제안한 시스템의 개괄적인 블록도

Fig 2. Overall block diagram of the proposed system 


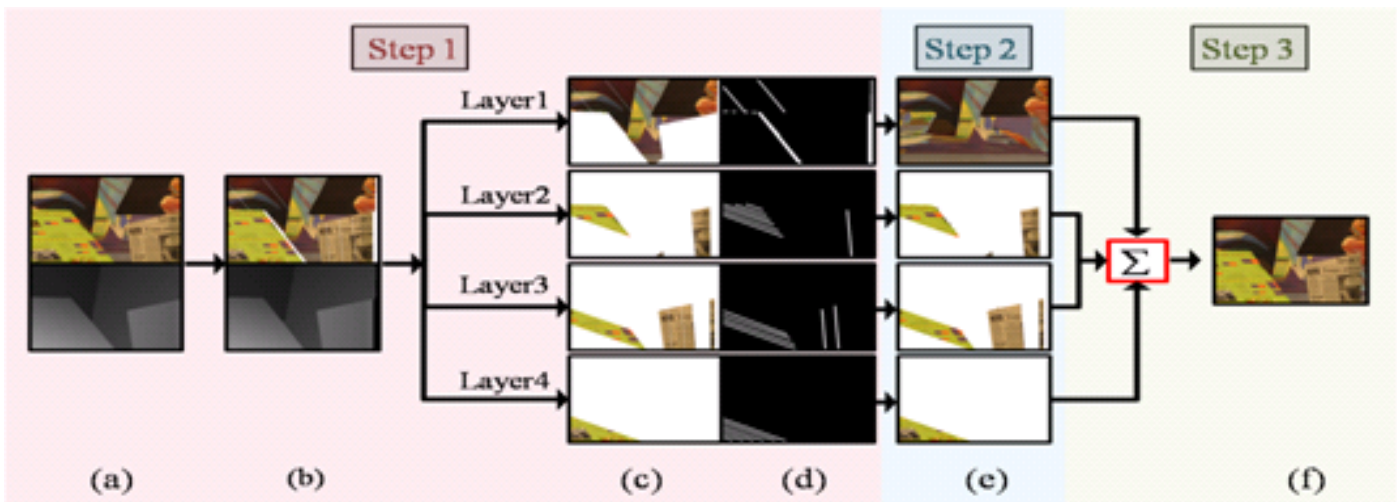

그림 3. 제안한 시스템의 처리 구조(n=4) (a) 기준 영상 Is와 상응하는 깊이 맵 Ds (b) 시점 이동 된 기준영상 Imov와 깊이영상 Dmov (c) 계층화 된 영상 I1, I2, ..., In (d) 계층화 된 가려짐 영역 Occ1, Occ2, .., Occn (e) 영상 인페인팅을 통해 가려짐 영역이 보간 된 각 계층 영상 (f) 합성 된 영상 Isyn

Fig 3. Procedure of the proposed system. $(n=4)$ (a) Source image Is and corresponding ground-truth depth image Ds. (b) Moved source image Imov and its depth image Dmov. (c) Layered images I1, I2, ..., In. (d) Layered occlusion Occ1, Occ2, ..., Occn. (e) Occlusion-filled layered images. (f) Synthesized image Isyn

으로 수행된다. 이 장에서는 각 단계의 세부적인 처리 과정 에 대해 설명하였다.

\section{1. 기준 영상으로 부터의 계층 영상 생성}

본 논문에서는 정렬된(aligned) 단일 기준 영상 Is와 상응 하는 잘 정제된 참 깊이 맵 $\mathrm{Ds}$ 가 존재함을 가정한다. 가상 시점 영상 합성을 위하여 기준 영상 Is 와 참 깊이 맵 $\mathrm{Ds}$ 의 모든 화소들은 깊이 값에 따라 수평방향으로 이동하게 된 다. 시점이동 된 Is와 Ds는 Imov와 Dmov가 되며 이 가상 시점 영상들은 각각 가려짐 영역을 가진다. 그 후, Imov를 Dmov의 값의 분포에 따라 k-means 알고리즘을 이용하여 여러 개의 계층 영상 $(\mathrm{I} 1, \mathrm{I} 2, \ldots, \mathrm{In})$ 과 각각에 해당하는 가려 짐 영역(Occ1, Occ2, ..., Occn)으로 나눈다. 이 때, 분할 될 계층 영상의 개수는 사용자 주관에 따라 적절한 값을 판단 하여 결정한다. 영상을 깊이 값에 따라 분할함으로써 나누 어진 각 계층 영상의 텍스처들은 각각 유사한 깊이 값을 가진다. 따라서 영상 인페인팅 시, 유사 깊이 값을 갖는 텍 스처만을 참고하게 되므로 분할하지 않은 경우보다 보다 우수한 가려짐 영역 보간 결과를 획득 할 수 있다. 이 때, 보간해야 할 가려짐 영역들은 시점 이동 방향의 반대편 방
향에 인접한 화소의 깊이 값을 참조하여 분할하여 처리한 다(Occ1, Occ2, ..., Occn). 일반적으로 시점 이동에 따라 새 로이 나타나는 가려짐 영역은 그 영역을 가리고 있던 부분 에 비해 멀리 있으므로 이와 같은 방법으로 가려짐 영역의 깊이값을 유추해 낼 수 있다.

\section{2. 각 계층 영상에 대한 영상 인페인팅}

각 계층 영상 $\mathrm{In}$ 상의 가려짐 영역 Occn은 모형 기반 (exemplar-based) 영상 인페인팅 방법에 의해 각각 보간된 다[4]. 이 방법은 각 계층상의 가려짐 영역이 모두 보간 될 때까지 수행되며 보간의 단계는 다음과 같다.
A. 패치(patch)의 우선순위 계산
B. 최우선순위(highest priority) 패치에 대한 유사 텍스처 차용
C. 우선순위 재계산

과정 $\mathrm{A}$ 에서는 보간 할 영역의 경계 상의 화소에 대해서 보간의 우선순위를 계산한다. 우선순위는 올바른 텍스처와 구조체 보간을 위하여 매우 중요하다. 패치의 우선순위는 
경계 상의 화소를 중심으로 하는 패치의 중심점이 갖는 신 뢰도(confidence)와 패치 내의 구조(structure)와 관련된 값 의 곱으로 결정된다.

우선순위 계산식은 다음과 같으며, 그림 4에 수식의 이해 를 돕기 위한 다이어그램을 도시하였다.

$$
P(p)=\frac{\sum_{q \in W_{p} \cap(I-O)} C(q)}{\left|W_{p}\right|} \cdot \frac{\left|\nabla I_{p}^{\perp} \cdot n_{p}\right|}{\alpha}
$$

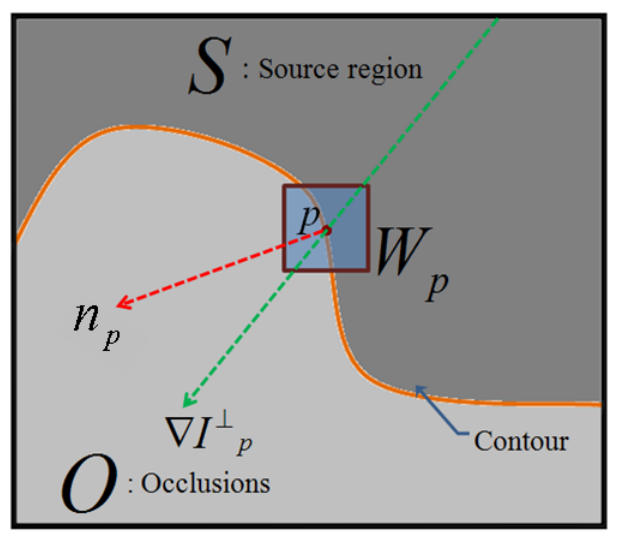

그림 4. 우선 순위 계산 방법에 관한 도시

Fig 4. Notation diagram of priority calculation

식 (1)에서, $\mathrm{P}(\mathrm{p})$ 는 보간 하고자 하는 화소 $\mathrm{p}$ 의 우선순위 를 의미하고, $\mathrm{C}(\mathrm{q})$ 는 패치내의 화소에서의 신뢰도 값, $\mathrm{O}$ 는 보간해야 할 영역을 나타낸다. $\mathrm{Wp}$ 는 패치를 의미하고 $|\mathrm{Wp}|$ 는 패치의 크기, $\nabla I^{\perp} p$ 는 영상내 구조체의 방향 단위 벡터, $\mathrm{np}$ 는 화소 $\mathrm{p}$ 에서의 경계(contour)에 대한 법선 단위 벡터를 나타낸다. $\alpha$ 는 정규화 상수(normalization constant)이고, 화소의 신뢰도는 소스영역(S)에 포함되는 화소에 대해서는 1 , 그외에는 0 으로 부여하였다. $\mathrm{P}(\mathrm{p})$ 값의 의미를 간단히 정 리하면, 영상 내 구조체의 방향과 일치하는 방향의 화소에 게 더 높은 우선순위를 부여함으로써 구조체를 더 올바르 게 복원 할 수 있도록 하는 값이며, 주변에 신뢰도가 높은 화소가 많이 분포하는 위치부터 보간 하게끔 함으로써 보 다 정확한 보간이 가능하도록 하는 우선순위 값이다.

최우선순위가 결정되면 그 화소에 대해 템플릿 정합 (template matching)을 통해 일정 범위 내의 패치와의 컬러 강도(color intensity)비교를 통해 유사도가 최대가 되는 영 역을 차용하여 목표 화소상의 패치영역과 혼합(blending)하 게 된다. 이 과정은 앞에서 언급한 과정 $\mathrm{B}$ 에 해당한다. 본 논문에서는 템플릿 정합의 방법으로 RGB 컬러 공간에서의 $\mathrm{SAD}$ (sum of absolute difference)를 사용하였다. 마지막으 로 과정 $\mathrm{C}$ 에서는 경계 상의 화소중의 최우선순위를 재계산 하며 목표 화소를 모두 보간 할 때까지 $\mathrm{A}$ 에서 $\mathrm{C}$ 의 과정을 반복한다.

\section{3. 보간 된 계층 영상들의 합성}

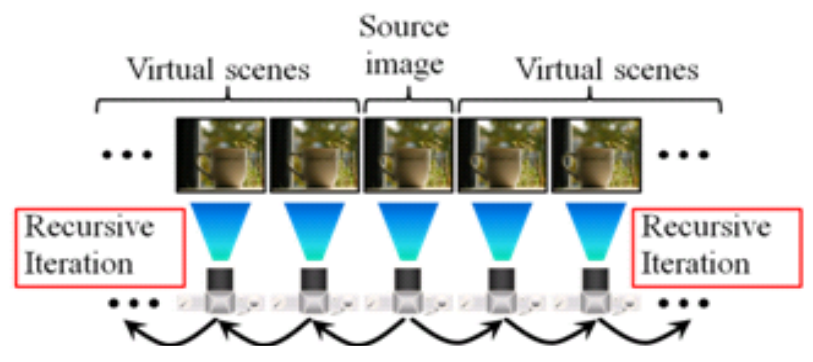

그림 5. 재귀적 반복 구조. 단계 1-3의 반복마다 단위 거리만큼 시점 이동 된 가상 시점 영상을 획득 할 수 있다. 원하는 시점의 개수가 획득 될 때까지 반복을 수행한다.

Fig 5. Recursive Iteration. System iterates overall steps recursively until desired view is synthesized

각 계층별로 개별적으로 보간 된 가려짐 영역 Occ'1, Occ' $2, \ldots, \mathrm{Occ}^{\prime} \mathrm{n}$ 은 최종적으로 하나의 영상으로 합성된다.

$$
I_{s y n}=I_{m o v} \cup \sum_{k=1}^{n} O c c_{k}^{\prime}
$$

식 (2)에서 $O c c_{k}{ }^{\prime}$ 는 각 계층에서의 보간 된 가려짐 영역 상의 텍스처 화소를 의미하며, Isyn은 이동 된 시점에서의 합성 완료된 영상을 나타낸다. Isyn은 그 다음의 반복과정 에서는 기준 영상으로 입력되게 되며 마찬가지로 Dmov또 한 다음의 과정에서 기준 참 깊이 영상으로 입력된다. 시스 템은 III장의 초반부에서 언급한 단계1-3을 재귀적으로 반 복함으로써 다시점 합성 영상을 획득한다(그림 5). 이와 같 이 재귀적인 방법으로 순차적으로 영상을 생성해 가며 결 
과 영상을 획득함으로써, 기준 영상에서 중간 시점 영상을 바로 생성하는 방법을 사용 할 때 변위의 크기가 큰 경우 발생하는 문제점인 막대형의 가느다란 형태의 물체가 가려 짐 영역 가운데 위치하게 되는 경우의 깊이 맵 보간 오류 문제를 해결 할 수 있었다.

\section{IV. 실험 결과 및 분석}

\section{1. 실험 결과}

4장의 기준 영상에 대한 결과를 그림 6부터 그림 8까지 나타내었다. 본 논문의 시스템에서는 영상의 상태에 따라 계층의 개수 $\mathrm{n}$ 을 영상에 따라 적절히 분할하였으며, 각 패 치의 크기는 가로, 세로 9로 설정하였다.

그림 6에서 사용된 기준 영상은 미들버리(middlebury) 스테레오 비전 홈페이지 ${ }^{[19]}$ 에서 제공되는 Venus영상이며
간단한 깊이 구조와 복잡한 텍스처 패턴을 가진다. 그림5에 서 가려짐 영역 부분에 대한 텍스처가 적절히 보간 되었음 을 확인 할 수 있다. 그림 7에서는 본 논문에서 제안한 계층 적 보간의 효율성을 나타내었다. 그림 7의 (a)는 계층적 보 간을 수행하지 않은 경우로 영상을 분할하지 않은 상태로 가려짐 영역에 대하여 Criminisi의 영상 인페인팅 알고리즘 을 적용한 결과이다. 다른 깊이를 갖는 텍스처의 고려로 인 하여 그림 7의 (b)의 영상 분할 후 인페인팅 한 결과에 비하 여 적절히 보간되지 않았음을 확인할 수 있다. 하지만 영상 내의 붉은 캔의 일부가 사라지는 문제가 발생하였다. 이는 가려짐 영역을 다수의 계층으로 나눌 때 각 가려짐 영역을 가상 카메라의 이동 방향에 대해 인접한 반대 방향 화소의 깊이 정보를 이용하여 계층화 하는데, 이때 부적절한 깊이 값을 참조하여 계층화함에서 발생한 문제점이다. 가려져 있던 부분에 대해서는 전혀 깊이 정보를 알 수 없으므로, 이는 한 장의 기준 영상과 깊이 맵 만으로는 해결하기 어려 운 문제라 생각 되며, 따라서 향후 연구에서 다룰 예정이다.

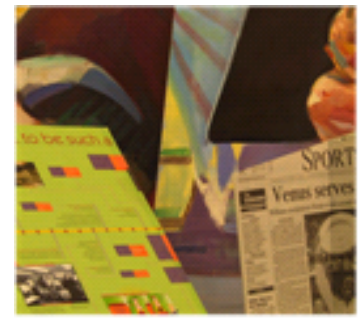

(a)

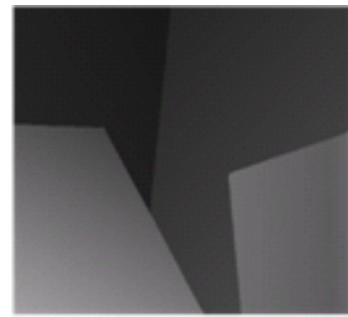

(b)

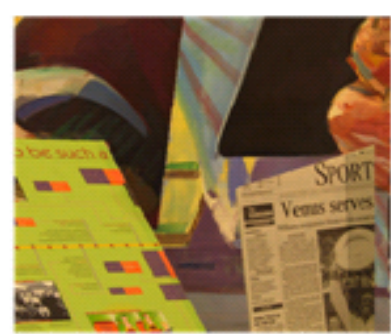

(c)

그림 6. Venus영상에 대한 결과 영상. [n=4] (a) 기준 영상 (b) 참 깊이 맵 (c) 합성 된 영상 Fig 6. Result of Venus. [n=4] (a) Source image (b) Ground-truth depth image (c) Synthesized image
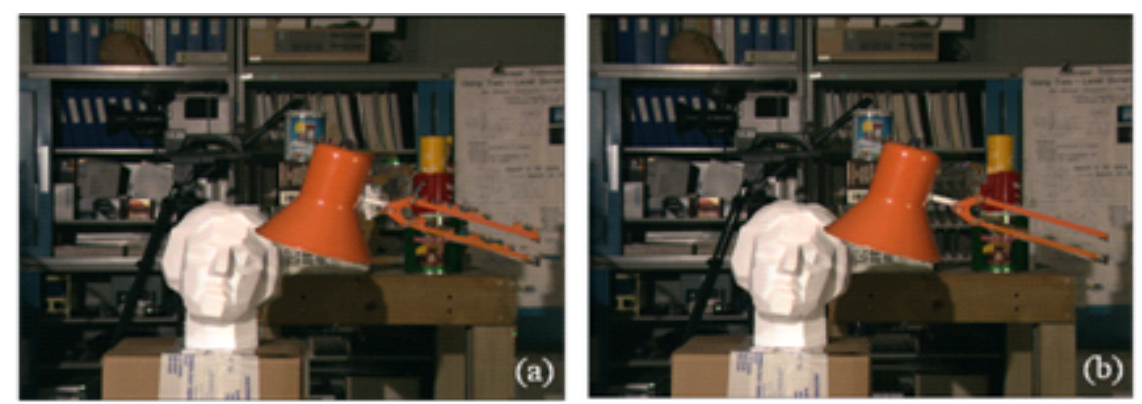

그림 7. 계층별 보간의 효율성. [n=7] (a) 계층별 보간을 수행하지 않은 경우 (b) 계층별 보간의 경우.

Fig 7. Effectiveness of our layered interpolation [n=7] (a) Case of non-layered inpainting (b) Case of our layered inpainting 

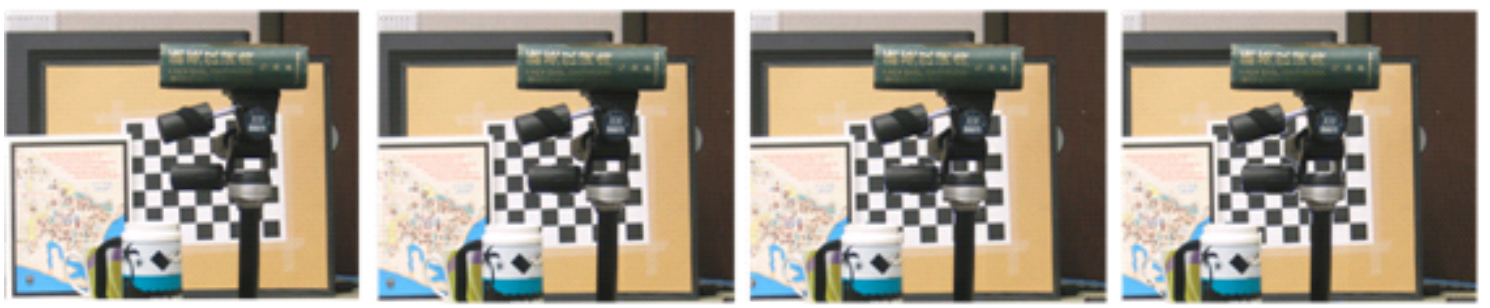

그림 8. 합성 된 영상 시퀀스. 가장 좌측의 영상은 기준 영상이며 그 우측 영상들은 계산 된 가상 시점의 영상이다. 가장 우측의 영상은 기준 영상에 대해 가장 큰 변위(disparity)를 갖는다. 각 영상에서, 배경 부분의 체스보드 패턴의 텍스처가 올바르게 보간 되었음을 확인 할 수 있다.

Fig 8. Synthesized image sequence. $(n=3)$ The far left image is the source image of 'Tripod'. The far right image has maximum disparity in the sequence. The chessboard pattern was observed without distortion

그림 8에서는 Tripod 영상에 대한 결과들을 나열하였다. 각 영상들은 스텝1-3의 각 반복마다 얻어진 영상 시퀀스이다. 각각의 영상에서 배경 부분의 체스보드 패턴의 구조가 왜 곡 없이 올바르게 생성되었음을 확인 할 수 있다.

\section{2. 결과에 대한 분석}

본 절에서는 PSNR(Peak-Signal to Noise Ratio)측정을 통하여 제안한 방법의 효율성을 입증하였다. PSNR은 현재 동영상 암호화 및 복호화 알고리즘 등의 품질 성능 지표로 사용되고 있다. 실험에 사용한 영상 데이터는 독일의 $\mathrm{HHI}$ 에서 제공한 MPEG test material for 3D video(leaving laptop) 및 Middlebury대학의 스테레오 비전 홈페이지 ${ }^{[19]}$ 에서 제공하는 Venus영상과 Poster영상을 사용하였다. 실험에 사용된 영상을 그림 9에 나타내었으며 PSNR은 식 (3), 식
(4)로 정의 된다.

$$
\begin{gathered}
P S N R_{d B}=10 \log _{10} \frac{\left(2^{b}-1\right)^{2}}{M S E} \\
b=\text { 데이터의 비트 수 }
\end{gathered}
$$

$$
M S E=\frac{1}{N} \sum_{i=0}^{n-1}\left(x_{i}-y_{i}\right)^{2}
$$

$N=$ 데이터의 수, $x_{i}$ 및 $y_{i}=$ 데이터 $x$ 및 $y$ 의 $i$ 번째 데이터

따라서 PSNR수치가 높을수록 원본 영상과 일치도가 높 음을 의미한다.

영상 압축이나 전송과는 달리 중간 시점 영상 합성은 비 교할 원본 영상이 없으므로 본 논문에서는 세 곳의 시점에 서 카메라로 찍은 영상을 이용하였다. 예를 들어, 왼쪽 카메 라부터 시작하여 카메라 1 , 카메라 2 , 카메라 3 으로 가정하고,
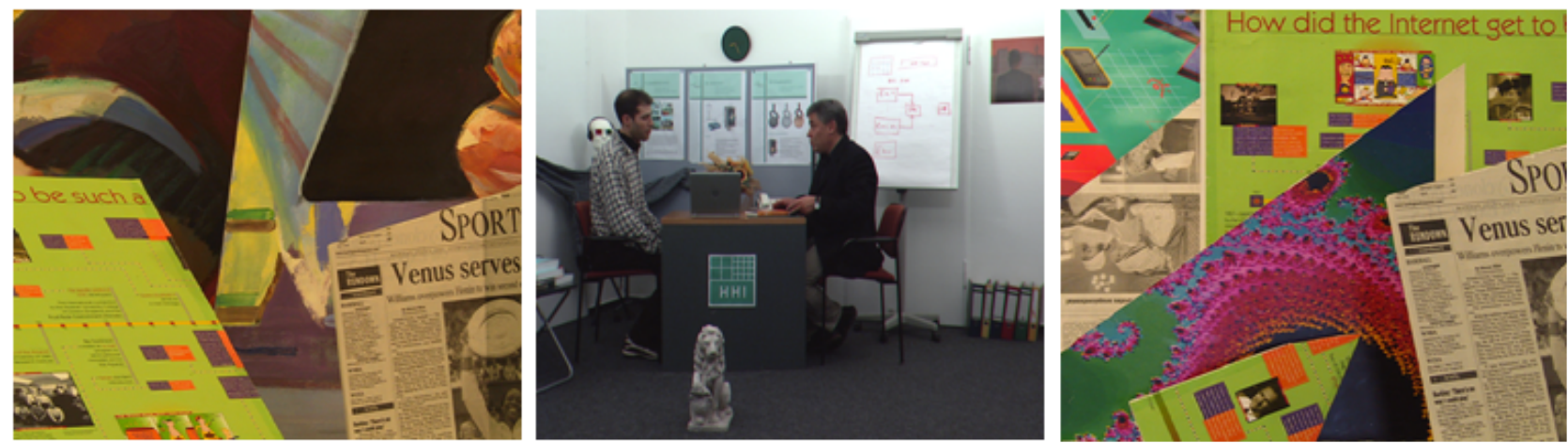

그림 9. 성능 실험에 사용된 원본 영상. (좌: Venus, 중: HHI. 우: Poster)

Fig 9. Used source images. (left: Venus, middle: HHI. right: Poster) 
카메라1과 카메라3에서 획득한 영상을 이용하여 카메라2 의 위치로 중간 시점을 생성한 후 카메라 2 의 영상과 합성된 중간시점 영상을 비교하였다. 또한 일반적인 방법에 대해 서 어느 정도의 성능 개선이 이루어 졌는지 확인하기 위해 서 그림 10 에서 기존의 방향성 보간 방법의 결과와 비교한 예시를 나타내었다.

표 1에서 각 영상에 대해 영상 인페인팅을 통한 보간 방 법이 기존의 방향성 보간 방법의 결과에 비하여 약 $0.3 \sim 1.2 \mathrm{~dB}$ 정도의 화질 개선 효과가 나타남을 확인 할 수 있었다. 각 영상에 대한 $\mathrm{dB}$ 측정 결과가 일정하지 않은 것
표 1. 각 영상/보간 방법 별 $\mathrm{PSNR}(\mathrm{dB})$

Table 1. Estimated PSNR scores of each image/method(dB)

\begin{tabular}{|c|c|c|c|}
\hline & Venus & HHI & Poster \\
\hline 방향성 보간 & 27.87 & 30.67 & 23.52 \\
\hline 인페인팅 보간 & 28.79 & 30.94 & 24.73 \\
\hline
\end{tabular}

은 각 영상 별 참조 시점 사이의 간격과 깊이 불연속의 차이 가 각각 달라서 발생한 가려짐 영역의 크기가 달랐기 때문 이다. 하지만 이는 각 화소의 컬러 강도 차이에 기반을 둔 수치적인 데이터이며 본 논문이 시청자가 가장 그럴 듯 하
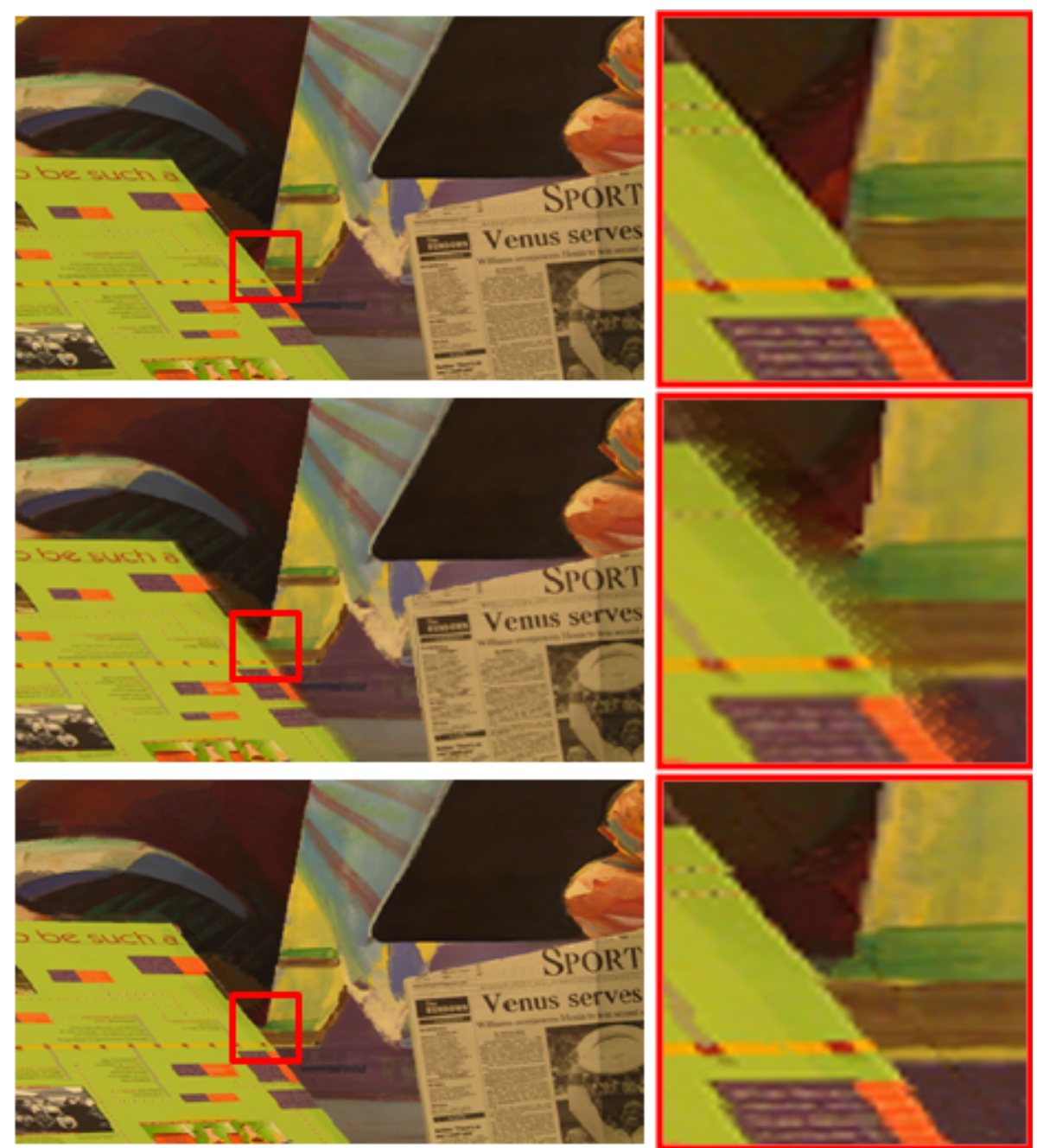

그림 10. 보간 방법에 따른 결과영상과 부분 확대 영상 (상: 원본 참조 영상, 중: 방향성 보간의 결과, 하: 인페인팅 보간의 결과)

Fig 10. Enlarged images of each interpolation method. (upper: source image, middle: directional interpolation, lower: image inpainting) 
다고 느끼는 가상 시점의 영상 생성을 목표로 함을 생각해 볼 때, 보간의 품질을 절대적으로 대변한다고 보기는 어렵 다. 인간의 시각은 영상 내의 컬러 강도의 차이뿐만 아니라 구조체의 배치, 경계의 불분명 여부 등의 여러 정보들을 종 합적으로 융합하여 영상의 품질을 판단하기 때문이다. 따라 서 본 논문에서는 표 2 에 제시된 3 가지 영상을 20 대와 30 대 의 전문가 7명(남자 7), 비전문가 3(남자2, 여자1)명에게 보 여주고 영상의 품질을 판단하도록 하였다. 품질 평가 방법 은 DSCQS(Double Stimulus continuous-quality Scale) ${ }^{[20]}$ 을 사용하였다. DSCQS방법은 다른 두 장의 영상을 두 번 반 복해서 보여주고 각 영상에 대한 0 에서 100 까지의 절대 점 수를 기록하는 방법이다. 최종적으로 얻어진 점수는 $\mathrm{MOS}$ (Mean Opinion Score)로 변환되고 MOS값을 바탕으로 상 대적인 품질을 측정 할 수 있다. 본 논문에서는 3 가지의 데 이터 셋을 무작위(random) 순서로 각각 10초씩 두 번 반복 하여 보여주고 영상의 전반적인 품질을 평가하였다(표 2). 사용자 평가 결과 기존의 방향성 보간에 비하여 인페인팅 을 통한 보간이 월등히 좋은 점수를 획득하였다. 이는 가려 짐 영역에 대하여 카메라 이동방향에 따라 이웃 화소를 참 조하여 보간하던 기존의 방향성 보간 방법에 비하여 인페 인팅을 통한 보간은 구조체와 경계 보존의 측면에서 우수 하기 때문에 사용자가 영상을 볼 때 훨씬 더 선명하다고 느끼기 때문인 것으로 생각된다. 다만 HHI영상에 대해서는 큰 점수 차이가 나지 않았는데 이는 실험에 사용한 $\mathrm{HHI}$ 스 테레오 영상이 다른 두 영상에 비하여 변위(disparity)가 작 기 때문에 영상에서 가려짐 영역이 차지하는 부분의 크기 가 비교적 작음에서 비롯되었다. 따라서 보간에 필요한 시 간 비용을 고려할 때 각 가상 시점 사이의 간격이 좁은 경우 에는 기존의 방향성 보간 또한 무난한 방법이라 생각되나, 생성 할 가상 시점 사이의 간격이 멀거나, 경우에 따라 시점 을 외삽(extrapolation)하여 생성해야 하는 경우에는 인페인

표 2. 각 영상/보간 방법에 따른 주관적 평가 결과(MOS)

Table 2. Subjective estimation results of each image/method(MOS)

\begin{tabular}{|c|c|c|c|}
\hline & Venus & HHI & Poster \\
\hline 방향성 보간 & 55.70 & 67.30 & 47.90 \\
\hline 인페인팅 보간 & 77.10 & 73.90 & 73.60 \\
\hline
\end{tabular}

팅 보간이 크게 효율적이라고 생각된다.

\section{V. 결 론}

본 논문에서는 한 장의 기준 영상과 상응하는 깊이 맵을 이용하여 가상의 다시점 영상을 생성해 내는 알고리즘을 제안하였다. 이는 계층별 보간과 영상 인페인팅 방법을 결 합함으로써 이루어진다. 영상 인페인팅 방법을 통하여 가 려짐 영역에 대해 가장 유사한 텍스쳐 패턴을 영상 내의 다른 부분에서 차용함으로써 보다 세밀하고 정확한 보간이 가능하며, 계층별 보간을 통해 실 공간상에 존재하는 깊이텍스처 연계성을 살려 보간 시의 텍스처 오류를 감소시킬 수 있었다. 실험 결과 단순히 시점 이동 방향에 대해 가려짐 영역 위치의 반대방향에 존재하는 화소들의 텍스쳐를 이용 하여 보간하는 방향성 보간 방법에 비하여 $0.3 \mathrm{~dB}$ 에서 $1.2 \mathrm{~dB}$ 정도의 품질 개선 결과를 얻을 수 있었으며, DSCQS 방법을 통한 사용자 주관 평가를 통하여 제안한 방법의 결 과가 시청자의 시각적인 거슬림 감소 측면에서 월등히 우 수함을 알 수 있었다. 또한 가려짐 영역의 크기가 클수록 그 효과가 두드러짐을 부수적으로 확인할 수 있었다.

그러나 본 논문에서 제안한 시스템은 몇 가지의 한계점 을 가지고 있으며 그것들은 향후 과제로 남겨두었다. 우선, 한 장의 영상으로는 가려짐 영역 부분의 깊이 값을 알 수 없음에서 발생하는 잘못된 텍스처 차용의 경우가 발생하였 다. 또한 제안한 방법은 깊이 맵의 품질에 의존적인 경향이 있기 때문에 올바른 가상 시점 영상 생성을 위해서는 정확 한 깊이 맵을 사용하여야 하는 한계점이 있으며, 본 논문에 서 사용한 인페인팅 알고리즘의 특성상 선형 탐색(linear search) 구조로 인하여 하나의 가상 시점 영상 생성 시 가려 짐 영역의 화소 수에 따라 적게는 수 초에서 많게는 수십 초가 걸리므로 실시간 시스템에 부적합한 단점이 있다.

현재 이러한 단점들을 극복한 보다 견고한 가상 시점 합 성 알고리즘을 개발하고 있다. 또한 속도적인 측면에서 GPU(Graphic Processing Unit)의 병렬처리 프로세스 구조 를 사용하여 실시간 합성이 가능하도록 개선하고 있으며, 이를 통해 보다 실용적인 시스템이 될 것으로 전망한다. 


\section{참 고 문 헌}

[1] C. Fehn, "Depth-image-based Rendering (DIBR), Compression and Transmission for a New Approach on 3D-TV," Proc. of SPIE, Stereoscopic Displays and Virtual Reality Systems XI, pp. 93-104, 2004.

[2] J. R. Ohm, "Stereo/Multi-view Video Encoding Using the MPEG Family of Standards," Proc. of Electronic Imaging, Invited Paper, 1999.

[3] A. Saxena, S. H. Chung, and A. Y. Ng, "3-D Depth Reconstruction from a Single Still Image," International Journal of Computer Vision (IJCV), 2007.

[4] A. Criminisi, P. Perez and K. Toyama, "Region Filling and Object Removal by Exemplar-based Image Inpainting," IEEE Trans. Image Processing, vol.13, no.9, pp. 1200-1212, 2004.

[5] S. Battiatoa, S. Curtib, M. L. Casciac, M. Tortorac and E. Scordatoc, "Depth Map Generation by Image Classification," Proc. of SPIE Electronic Imaging, pp. 95-104, 2004.

[6] C. Fehn and P. Kauff, "Interactive Virtual View Video (IVVV): The Bridge between 3D-TV and Immersive TV," Proc. of SPIE Three-Dimensional TV, Video and Display, pp. 14-25, 2002.

[7] M. M. Oliveira, B. Bowen, R. McKenna and Y. S. Chang, "Fast Digital Image Inpainting," Proc. of the International Conference on Visualization Imaging and Image Processing, pp. 261-266, 2001.

[8] A. Efros and T. Leung, "Texture Synthesis by Non-parametric Sampling," Proc. of IEEE International Conference on Computer Vision, pp. 1033-1038, 1999.

[9] A. Efros and W. T. Freeman, "Image Quilting for Texture Synthesis and Transfer," Proc. of ACM SIGGRAPH, pp. 341-346, 2001.
[10] J.-F. Lalonde and A. Efors, "Using Color Compatibility for Assessing Image Realism," Proc. of IEEE International Conference on Computer Vision, pp. 1-8, 2007.

[11] I. Drori, D. Cohen-Or and H. Yeshurun, "Fragment-Based Image Completion," Proc. of ACM SIGGRAPH, Vol. 22, pp. 303-312, 2003.

[12] S. Avidan and A. Shashua, "Novel View Synthesis by Cascading Trilinear Tensors," IEEE Trans. Visualization and Computer Graphics, vol.4 no.4, pp.293-306, 1998.

[13] D. Scharstein, "View Synthesis Using Stereo Vision," Springer Press, 1999.

[14] J. Sun, L. Yuan, J. Jia and H. Y. Shum, "Image Completion with Structure Propagation," Proc. of ACM SIGGRAPH, Vol.24, pp. 861-868, 2005.

[15] M. Bleyer, M. Gelautz, and C. Rother, C. Rhemann, "A stereo approach that handles the matting problem via image warping," Computer Vision and Pattern Recognition, 2009.

[16] K. Wegner and O. Stankiewicz, "Similarity measures for depth estimation," Proc. of 3DTV Conference: The True Vision," - Capture, Transmission and Display of 3D Video, 2009.

[17] K.-J. Oh, S. Yea, and Y.-S. Ho, "Hole-filling method using depth based in-painting for view synthesis in free viewpoint television (FTV) and 3D video," Proc. of Picture Coding Symposium (PCS), 2009.

[18] L. Zhang, W.J. Tam, "Stereoscopic image generation based on depth images for 3D TV," IEEE Trans. on Broadcasting, vol.51, no.2, pp. 191-199, 2005

[19] http://vision.middlebury.edu/stereo

[20] ITU-R Recommendation BT.500-10, "Methodology for the Subjective Assessment of the Quality of Television Pictures," 2002.

저 자 소 개

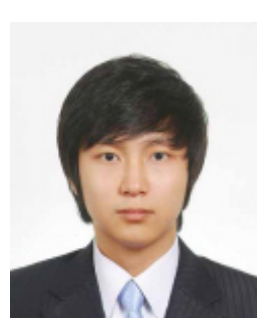

김 용 진

- 2007년 : 한양대학교 전자전기컴퓨터공학과 학사 졸업

- 2009년 : 한양대학교 전자통신컴퓨터공학과 석사 졸업

- 2009년 현재 : (주) 아이너스기술 연구원

- 주관심분야 : 3 차원 영상처리, 영상 합성, 3 차원 디스플레이, 증강현실

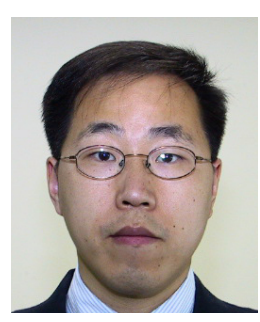

이 상 화

- 1994년 : 서울대학교 전자공학과 학사 졸업

- 1996년 : 서울대학교 전자공학과 석사 졸업

- 2000년 : 서울대학교 전기공학과 박사 졸업

- 2009년 현재 : 서울대학교 전기공학부 BK21 연구교수

- 주관심분야 : 영상처리, 영상압축, $\mathrm{HCl}$, 컴퓨터그래픽스비전, 패턴인식 
저 자 소 개

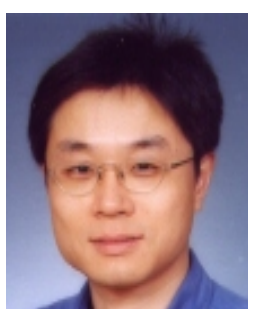

박 종 일

- 1987년 : 서울대학교 전자공학과 학사 졸업

- 1989년 : 서울대학교 전자공학과 석사 졸업

- 1995년 : 서울대학교 전자공학과 박사 졸업

- 1992년 1994년 : 일본 NHK방송기술연구소 객원연구원

- 1995년 1996년 : 한국방송개발원 선임연구원

- 1996년 1999년 : 일본 ATR지능영상통신연구소 연구원

- 1999년 현재 : 한양대학교 전자통신컴퓨터공학과 교수

- 주관심분야 : 가상현실, 증강현실, $\mathrm{HCl}, 3$ 차원 영상처리, 컴퓨터그래픽스비전 